\title{
ADIPOSE TISSUE: THE RENAISSANCE MARKED BY FOUR PARADIGM SHIFTS
}

\author{
Gorana Ranćić ${ }^{1}$, Marco Fiore ${ }^{2}$, Rouzha Pancheva ${ }^{3}$, Neşe Tuncel ${ }^{4}$, Jerzy Beltowski ${ }^{5}$, Marin Zhelezov ${ }^{6}$, \\ Peter I. Ghenev ${ }^{7}$, Alexander Hinev ${ }^{8}$, Plamen Panayatov ${ }^{9}$, Nikolay Evtimov ${ }^{10}$, Stanislav Yanev ${ }^{11}$, \\ Anton B. Tonchev ${ }^{6}$, Luigi Aloe ${ }^{2}$, and George N. Chaldakov ${ }^{6 *}$ \\ 'Department of Histology and Embryology, Medical Faculty, Niš, Serbia \\ ${ }^{2}$ Institute of Cellular Biology and Neurobiology, CNR, Rome, Italy \\ ${ }^{3}$ Department of Hygiene, Faculty of Public Health, Medical University, Varna, Bulgaria \\ ${ }^{4}$ Department of Physiology, Medical Faculty, Osmangazi University, Eskişehir, Turkey \\ ${ }^{5}$ Department of Pathophysiology, Medical University, Lublin, Poland \\ ${ }^{6}$ Laboratory of Cell Biology, Department of Anatomy and Histology, Medical University, Varna, Bulgaria \\ ${ }^{7}$ Department of General and Clinical Pathology, Medical University, Varna, Bulgaria \\ ${ }^{8}$ Urology Clinic, St Marina University Hospital, Varna, Bulgaria \\ ${ }^{9}$ Department of Cardiac Surgery, St Marina University Hospital, Varna, Bulgaria \\ ${ }^{10}$ Urology Clinic, St Anna University Hospital, Varna, Bulgaria \\ ${ }^{11}$ Laboratory of Drug Toxicology, Institute of Neurobiology, Bulgarian Academy of Sciences, Sofia, Bulgaria
}

One of the biggest recent achievements in the study of cardiometabolic diseases (atherosclerosis, hypertension, obesity, type 2 diabetes mellitus, metabolic syndrome, and Alzheimer's disease, which is recently viewed as type 3 diabetes, see below) is associated with the "rediscovery" of a neglected tissue, the adipose tissue.

Here we will Dance Round four paradigm shifts in the study of adipose tissue.

In 1962, Thomas S. Kuhn published his book The Structure of Scientific Revolutions (1st edition, University of Chicago Press, Chicago, USA). Its publication was a landmark event in the history and philosophy of scientific knowledge (epistemology). Kuhn challenged the prevailing view of "normal science" which was viewed as "development-by-accumulation" of accepted facts and concepts leading - most often - to epistemological paralysis, we dubbed it neophobia (the term also used for children above the age of 1 year). Kuhn argued for a model in which a period of such conceptual continuity in normal science were interrupted by a period of revolutionary science leading to a new paradigm, an event he designated paradigm shift.

At epistemological level, the adipose tissue has undergone four major paradigm shifts in last 20 years, which "upregulated" it above the horizon. Consequently, adipose tissue takes center stage in so many diseases that it leaves most scientists and medical doctors astonished. 


\section{The first paradigm shift: never before has adipose tissue been so active}

While considered a passive lipid storage-release tissue by most cell biologists and pathologists for a long period of time, adipose tissue is now appreciated as the biggest endocrine and paracrine organ of the human body (1-7) (Table 1). The discovery of leptin, an $o b / o b$ gene encoded adipocyte-secreted cytokine, by Jeffrey Friedman and colleagues in 1994 (1) marked this revolutionary event, which opened the first adipose-brain talk (Table 2). Here the pioneering contribution of Douglas Coleman (1931-2014) has to be acknowledged. His work established the first clues to a genetic component in obesity. In the 1970s, Coleman conducted a series of experiments that led him to propose the existence of a satiety factor that would account for obesity and type 2 diabetes among certain laboratory mice.
Onward, it is demonstrated that adipose tissue is able to send and receive different types of protein and non-protein signals, thus communicating with many organs in the body. And, in effect, contributing to the control of lipid and glucose metabolism, inflammation, immunity, reproduction, hemostasis, vascular smooth muscle contraction-relaxation, learning, memory and emotions among many other biological functions. Altogether, this matter was conceptualized in two novel research fields, adipobiology and adipopharmacology $(2,4)$.

\section{The second paradigm shift: external versus internal adipose depot}

This paradigm shift derived from the study of Jeffrey Bell and colleagues (8) who have scanned nearly 800 people with magnetic resonance imaging (MRI) technique, aimed at obtaining

Table 1. An example of paradigm shifts in studying adipose tissue*

\section{FROM}

The adipose tissue is a lipid storage-release organ involved in obesity

TO

Adipose tissue is an endocrine, paracrine and autocrine organ

Adipose tissue is a neuroendocrine organ

Adipose tissue is a steroidogenic organ

Adipose tissue is an immune organ

Adipose tissue is a source of and target for inflammatory mediators

Adipose tissue produces all components of rennin-angiotensin system

Adipose tissue is a storage-release organ of xenobiotics, xenobiotic-metabolizing cytochromes P450 being expressed in adipose tissue**

Adipose tissue is thus involved in numerous diseases beyond obesity

- Atherosclerosis, Hypertension, Type 2 diabetes, Nonalcoholic fatty liver disease, Polycystic ovarian syndrome, Obstructive sleep apnea syndrome***, Cancer, Osteoarthritis, Alzheimer's disease, Depression

*Modified from (6).

**See (7), also Carmen Purdel and colleagues' review in this volume of Adipobiology.

*** See Gülnur Ozturk and colleagues' review in this volume of Adipobiology.

Table 2. Adipose-brain talk: examples of neuromediators in leptin signaling

\begin{tabular}{|c|l|}
\hline \multicolumn{1}{|c|}{ Anorexigenic pathway $\uparrow$} & \multicolumn{1}{|c|}{ Orexigenic pathway $\downarrow$} \\
\hline Proopiomelanocortins & Neuropeptide tyrosine (NPY) \\
Melanocortin 4 & Agouti-related protein \\
a-melanocyte stimulating hormone & Endocannabinoids \\
Brain-derived neurotrophic factor & \\
\hline
\end{tabular}


map of WAT. The authors demonstrated that as many as $45 \%$ of women and nearly 60 percent of men scanned have normal scores of the body mass index (BMI, $20-25 \mathrm{~kg} / \mathrm{m}^{2}$ ). These people are thin outside (TO), while actually have excessive levels of internal adipose tissue - they are fat inside (FI), hence TOFI phenotype of body fatness (Table 3). Noteworthy, TOFI phenotype was also found among people who are professional models. TOFI may thus be considered a specific, "invisible" expression of both Homo obesus and Homo diabesus $(6,9)$.

Table 3. Adipotopography (fat map): variations+

\begin{tabular}{|ll|}
\hline TOFI $^{* *}$ & thin outside, fat inside \\
TOTI $^{* * * *}$ & thin outside, thin inside \\
FOFI $^{*}$ & fat outside, fat inside \\
FOTI $^{* *}$ & fat outside, thin inside
\end{tabular}

+ The number of asterisks indicates the quality of cardiometabolic health, as related to adipose tissue. From (9).

\section{The third paradigm shift: white versus brown adipocytes}

This paradigm shift features the increasing significance of brown adipose tissue in health and disease.

Adipose tissue is a very plastic tissue, being constantly remodeled along with weight gain and weight loss. It is a dynamic cellular and extracellular matrix assembly composed of adipocytes, stromal vascular cells (fibroblasts, endothelial cells, macrophage, mast cells and other immune cells) and matrix components, also rich in sympathetic nerve fibers, blood vessels, and stem cells, the latter being with great regenerative power. In human body, there are two major subtypes of adipose tissue, white adipose tissue (WAT) and brown adipose tissue (BAT). While WAT stores energy, BAT has the ability to dissipate energy by producing heat. BAT-mediated increase in energy expenditure is realized by uncoupling respiration from ATP synthesis via uncoupling protein 1 (UCP1), which is the signature protein of brown adipocytes.

Until 10-15 years ago BAT was considered to be biologically active in neonates and young children generating heat during cold exposure by adaptive thermogenesis to maintain normal body temperature. And then regressed with aging by transforming into WAT. At that time, it was demonstrated with ${ }^{18} \mathrm{~F}$-fluorodeoxyglucose (FDG), an intravenously administered radioactive glucose analog, in positron emission tomography (PET) and computed tomography (CT) (PET-CT fusion) scans that the main BAT depots were disseminated throughout the human body (around the aorta, common carotid artery, bra- chiocephalic artery, kidney, adrenal glands, liver, pancreas; in anterior mediastinum, supraclavicular fossa, axilla and thoracic paravertebral loci, also between neck muscles). The magnitude of ${ }^{18} \mathrm{FDG}$ uptake by BAT was reported to increase with exposure to low temperature, to be higher in women than men, and to decrease with age and body fat mass (reviewed in 10,11).

Animal studies have shown that activation of BAT counteracts diet-induced weight gain and related disorders such as type 2 diabetes and metabolic syndrome; it may also be the case for humans (10-12). The knowledge about WAT and BAT were enriched with their relatives, namely brite (brown in white) and bruscle (brown in skeletal muscle) adipocytes (13).

Taken together, brown adipobiology as well as stem cell adipobiology became new, optimistic challenges in biomedical research.

\section{The emerging fourth shift: adipose-Alzheimer?}

Recent results have revealed that adipose cells secrete various neurotrophic factors, including nerve growth factor (NGF) and brain-derived neurotrophic factor (BDNF) (14-16; 17 for the role of NGF in amyloid precursor protein/APP processing) (Table 4). Likewise, a growing body of evidence demonstrated a link between obesity, adipokines and the pathogenesis of Alzheimer's disease (18-22). Noteworthy, it was found an extraneuronal production of APP including in the adipose tissue (2325). Further, streptozotocin model of inducing experimental diabetes (26) is now also applying in the induction of Alzheimer's disease $(27,28)$. Thus, the hypothesis of adipose tissue as a third brain (29) and consequently of adipose-Alzheimer may sounds more plausible at present.

Table 4. Selected list of adipose-secreted neurotrophic factors: neuroadipokines

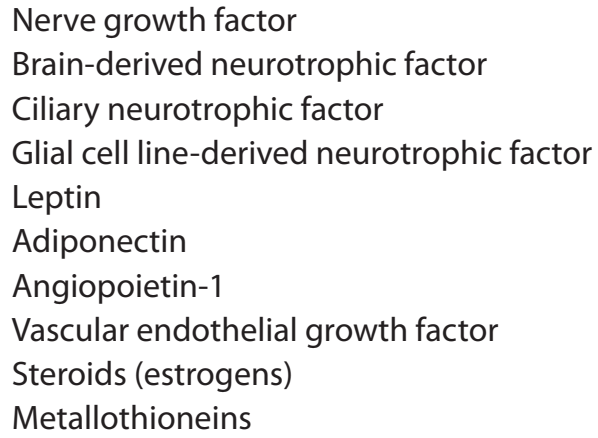

\section{Conflict of interest}

The authors declare no conflict of interest. 


\section{References}

1. Zhang YY, Proenca R, Maffei M, Barone M, Leopold L, Friedman JM. Positional cloning of the mouse obese gene and its human homologue. Nature 1994; 372: 425-432.

2. Chaldakov GN, Stankulov IS, Hristova MG, Ghenev PI. Adipobiology of disease: adipokines and adipokine-targeted pharmacology. Curr Pharm Des 2003; 9: 1023-1031.

3. Schäffler A, Schölmerich J, Buechler C. The role of "adipotrophins" and the clinical importance of a potential hypothalamic-pituitary-adipose axis. Nat Clin Pract Endocrinol Metab 2006; 2: 374-383.

4. Töre F, Tonchev AB, Fiore M, Tunçel N, Atanassova P, Aloe L, Chaldakov GN. From adipose tissue protein secretion to adipopharmacology of disease. Immun Endoc Metab Agents Med Chem 2007; 7: 149-155.

5. Renes J, Mariman E. Application of proteomics technology in adipocyte biology. Mol Biosyst 2013; 9: 1076-1091.

6. Chaldakov GN, Aloe L, Tonchev AB, Fiore M. From Homo obesus to Homo diabesus: Neuroadipology insight. In: C. Nóbrega, R. Rodriguez-López, editors. Molecular Mechanisms Underpinning the Development of Obesity. Chapter 11. pp 167-178. Springer International Publishing, Switzerland, 2014. DOI 10.1007/978-3-319-12766-8_11

7. Chaldakov GN, Yanev S, Georgiev V. Toxicology of adipose tissue (adipotoxicology) or adipose tissue as a "toxicrine" organ. In: G.N. Pierce et al, editors. Advanced Bioactive Compounds Countering the Effects of Radiological, Chemical and Biological Agents. Chapter 22. pp 253-260. NATO Science for Peace and Security Series A: Chemistry and Biology, Springer Science+Business Media Dordrecht 2013. DOI: 10.1007/978-94-007-6513-9_22

8. Louise TE, Saeed N, Hajnal JV, Brynes A, Goldstone AP, Frost $\mathrm{G}$, et al. Magnetic resonance imaging of total body fat. J Appl Physiol 1998; 85: 1778-1785.

9. Ranćić G, Petrovic A, Sekulovic-Stefanovic L, Bojamic V, Ghenev PI. Adipotopogrpahy: TOFI versus TOTI, or a hidden Homo obesus [Abstract]. In: The First International Symposium on Adipobiology and Adipopharamacology, Varna, Bulgaria, 20 October 2007. pp 13-14.

10. Frühbeck G, Becerril S, Sáinz N, Garrastachu P, GarcíaVelloso MJ. BAT: a new target for human obesity? Trends Pharmacol Sci 2009;30:387-396

11. Sacks H, Symonds ME. Anatomical locations of human brown adipose tissue functional relevance and implications in obesity and type 2 diabetes. Diabetes 2013; 62: 1783-1790. DOI: $10.2337 / \mathrm{db} 12-1430$

12. Iacobellis G, Di Gioia C, Petramala L, Chiappetta C, Serra V, Zinnamosca L. et al. Brown fat expresses adi- ponectin in humans. Int $J$ Endocrinol 2013: 126751. DOI: $10.1155 / 2013 / 126751$

13. Giralt M, Villarrova F. White, brown, beige/brite: different adipose cells for different functions? Endocrinology 2013; 154: 2992-3000.

14. Sornelli F, Fiore M, Chaldakov GN, Aloe L. Adipose tissuederived nerve growth factor and brain-derived neurotrophic factor: results from experimental stress and diabetes. Gen Physiol Biophys 2009; 28: 179-183. PMID: 19893098

15. Hausman GJ, Barb CR, Dean RG. Patterns of gene expression in pig adipose tissue: insulin-like growth factor system proteins, neuropeptide Y (NPY), NPY receptors, neurotrophic factors and other secreted factors. Domest Anim Endocrinol 2008; 35: 24-34.

16. Yanev S, Aloe L, Fiore F, Chaldakov GN. Neurotrophic and metabotrophic potential of nerve growth factor and brainderived neurotrophic factor: Linking cardiometabolic and neuropsychiatric diseases. World J Pharmacol 2013; 2: 9299. DOI: 10.5497/wjp.v2.i4.92

17. Triaca V. Homage to Rita Levi-Montalcini. Molecular mechanisms of Alzheimer's disease: NGF modulation of APP processing. Adipobiology 2013; 5: 7-18. DOI: http:// dx.doi.org/10.14748/adipo.v5.292

18. de la Monte S, Wands JR. Alzheimer's disease is type 3 diabetes - evidence reviewed. J Diabetes Sci Technol 2008; 2: 1101-1113.

19. Naderali EK, Ratcliffe SH, Dale MC. Review: obesity and Alzheimer's disease: a link between body weight and cognitive function in old age. Am J Alzheimer's Dis Other Demen 2009; 24: 445-449.

20. Frisardi V, Solfrizzi V, Seripa D, Capurso C, Santamato A, Sancarlo D, et al. Metabolic-cognitive syndrome: A crosstalk between metabolic syndrome and Alzheimer's disease. Ageing Res Rev 2010; 9: 399-417.

21. Dar TA, Sheikh IA, Ganie SA, Ali R, Singh LR, Gan SH, et al. Molecular linkages between diabetes and Alzheimer's disease: Current scenario and future prospects. CNS Neurol Disord Drug Targets 2014; 13: 290-298.

22. Kiliaan AJ, Arnoldussen IAC, Gustafson DR. Adipokines: a link between obesity and dementia? Lancet Neurol 2014; 13: 913-923.

23. Truran S, Franco DA, Roher AE, Beach TG, Burciu C, Serrano G, et al. Adipose and leptomeningeal arteriole endothelial dysfunction induced by $\beta$-amyloid peptide: a practical human model to study Alzheimer's disease vasculopathy. J Neurosci Methods 2014; 30: 235:123-129. DOI: 10.1016/j.jneumeth.2014.06.014. 
24. Puig KL, Combs CK. Expression and function of APP and its metabolites outside the central nervous system. Exp Gerontol 2013; 48: 608-611. DOI: 10.1016/j.exger.2012.07.009

25. Puig KL, Floden AM, Adhikari R, Golovko MY, Combs CK. Amyloid precursor protein and proinflammatory changes are regulated in brain and adipose tissue in a murine model of high fat diet-induced obesity. PLoS One 2012;7:e30378. DOI: 10.1371/journal.pone.0030378.

26. Sposato V, Manni L, Chaldakov GN, Aloe L. Streptozotocininduced diabetes is associated with changes in NGF levels in pancreas and brain. Arch Ital Biol 2007; 145:87-97.

27. Wang X, Yu S, Hu JP, Wang CY, Wang Y, Lui HX, et al.
Streptozotocin-induced diabetes increases amyloid plaque deposition in $\mathrm{AD}$ transgenic mice through modulating AGEs/RAGE/NF- $\kappa B$ pathway. Int J Neurosci 2014;124:601608. DOI: 10.3109/00207454.2013.866110.

28. Gao C, Lui Y, Jiang Y, Ding J, Li L. Geniposide ameliorates learning memory deficits, reduces tau phosphorylation and decreases apoptosis via GSK3 $\beta$ pathway in streptozotocininduced Alzheimer rat model. Brain Pathol 2014; 24:261269. DOI: 10.1111/bpa.12116.

29. Chaldakov GN, Fiore M, Tonchev AB, Hristova MG, Ranĉî $\mathrm{G}$, Aloe L. The adipose tissue as a third brain. Obesity Metab 2009; 5: 94-96. 